\title{
The Body Image Battle: Are adolescent boys influenced by their parents and peers?
}

\author{
Aditi Deshmukh ${ }^{1}$, Merrita Anju Joseph ${ }^{2}$, Sweta Mookerjee ${ }^{3}$ \\ 1,2,3 TYBA Psychology Student, Department of Psychology, Sophia College for Women, Mumbai \\ E-mail - sweta.mookerjee@gmail.com
}

\begin{abstract}
Background: Previous studies concerning body image have established that it is prevalent and faced by many, especially girls. Early accounts of body image focused primarily on women and girls, thereby largely excluding males. However, the fact of the matter is that boys are just as vulnerable to experiencing body image issues. This study aims to understand the prevalence of body image issues among adolescent boys in Mumbai.

Methodology: The study employed questionnaires and interviews and explored the influence of parents and peers in forming this construct. 173 boys (age group 12-20) -from schools (for early adolescents) and colleges (for late adolescents) located in Western Suburbs of Mumbai. The incidental sampling method was used. 75 participants belonged between the age range 12-15 years were early adolescents and 98 participants belonged between the age range of 16-20 years were late adolescents.

Results: Significant results were obtained confirming the influence that parents had on early adolescents and peers had on late adolescents. Body image issues for boys should be addressed more seriously in the country.

Conclusion: The body image acceptance differences were not found to be significant across the two groups, males showed relatively higher levels of body image acceptance compared to females.
\end{abstract}

Key Words: Body Image, Parents, Peers, Early Adolescence, Late Adolescence, adolescents

(Paper received $-1^{\text {st }}$ April 2017, Peer review completed $-14^{\text {th }}$ April 2017, Accepted $-16^{\text {th }}$ April 2017)

\section{INTRODUCTION}

\section{History of Body Image}

The notion of body image as a psychological phenomenon was originally established in 1935 , by the Austrian psychiatrist Paul Ferdinand Schilder (1886- 1940), who defined body image as the mental images that individuals have of their own bodies explain the way their bodies are introduced to them. According to the psychiatrist, one's mental body image is established by senses, ideas and feelings that, most of the time, are unconscious. This representation is built and rebuilt throughout life [1].

Body image as a topic was exclusive to women and has only recently begun to include males and their perceptions of their body. Until, the 1980's body image was linked solely with women due to the objectification and prevalence of women in myths, pop culture and so on. The male body was first portrayed in the form of life sized nude statues in Greek and Roman sculptures. The ideal body image consisted of broad shoulders and a waistline that tapered towards the hips and formed a "V". This style of representing men was named "Daedalic" after the first Greek sculptor - Daedalus [2]. 
The male body continued to be idolized in formal art and sculptures, but made its way to mainstream media only by 1980 's. Lately, the past three decades have witnessed a dramatic shift in this trend and the voices of males regarding their body image are no longer silenced. The extent to which emphasis is laid on males concerning body image is still relatively much more dormant than that for women [3].

\section{Types of Body Image}

1. Positive body image: A positive body image is when a person is in a position to accept, embrace and respect his/her own body. It is very important because it protects a person from suffering through low esteem and makes them resilient to eating disorders. A positive body image improves self-esteem, self-acceptance and promotes a healthy outlook and behaviour [4].

2 Negative body image: A negative body image refers to an impractical view of how one sees himself/herself. Constant obsession and dissatisfaction with one's body can result in unnatural and unhealthy attitude towards eating and exercise which may not even produce the desired outcome of losing weight. The failure to reach this unrealistic goal causes the individual to feel shame, guilt, and disappointment and finally in extreme measures, develop an eating disorder like Anorexia, Bulimia Nervosa, and Body or Muscle Dysmorphic Disorder and so on [5].

\section{Body image and adolescence}

Puberty is a challenging period for adolescents with complex processes like dealing with rapid physical changes, self-consciousness, hormonal and emotional changes that make it difficult to cope with. During adolescence, both males and females become extremely preoccupied and sensitive about their size and physical appearance. A high value is placed on physical attractiveness. Adolescents critically and harshly compare themselves with an imagined or socially determined standard and body dissatisfaction becomes inevitable. In boys puberty is expected to bring about changes that form the core characteristics in men height, broadness, strength and many more. A delayed or premature development of the same in boys poses one of the greatest challenges to a healthy image [6-7].

A study showed that nearly 18 percent of boys are very concerned about their weight and physique. They were also at a greater risk for a number of negative consequences such as greater probability of being depressed, or indulging in high-risk behaviors like binge drinking and drug use. Results were such that amongst the boys who were very worried about their weight, half were concerned about gaining more muscle and about one third were concerned with both being thin and muscular and less than 15 percent were concerned only with thinness. Thus throwing light on the fact that while girls usually want to lose weight, boys are likely to want to gain muscle as opposed to lose it [8].

\section{Social Comparison Process}

Social Comparison theory was proposed by Leon Festinger [9] and the theory proposes that human being innately possess a drive to evaluate his opinions and his abilities. A study explored the use of social comparison appraisals in adolescents' lives with particular reference to enhancement appraisals which can be used to counter threats to the self. Social comparison theory has been increasingly used in quantitative research to understand the processes through which societal messages about appearance influence adolescents' body image. Little is known about the comparison processes used in their daily lives- to whom individuals compare (the target), on what individuals compare (the attribute) and how they compare (comparison appraisal). Based on the analysis of 20 in-depth grounded theory interviews with 12- to 14-year old boys and girls, it was suggested that comparison processes are used for the purpose of identity development (core category). Peers play an important part in making sense of media images and messages and provide comparison targets themselves. Adolescents are aware of societal standards and pressures and use a range of enhancement appraisals [10].

\section{Parental influence on Body Image}

It is during adolescence that parents start becoming less positive and more critical about the child's appearance, eating habits and physical activity. Problems arise when parents start becoming over 
concerned with their child being too thin or too fat and this further makes the adolescent feel inadequate and they engage in constant dieting and unhealthy weight control methods, furthermore this is also quite harmful to their self-esteem. Parental influences have two mechanisms of influencing adolescent boys Indirect method in the form of parent modeling and Direct method in the form of comments regarding weight related attitudes [11].

\section{Peer influence on Body Image}

Adolescence is the phase of life in which peer relationships become vital for coping with the surmounting changes. Adolescents spend a significant amount of time with their peers and therefore they help in shaping the attitudes and behaviors of the young adult. The dependence on peers is so strong that they feel a compulsive need to communicate with their counterparts. As the cognitive abilities of adolescent boys expand during adolescence, they are better able to judge and compartmentalize people into different categories without knowing them well. This helps adolescents to successfully judge fellow colleagues and choose their own peer group based on the similarity of evaluated traits. The need to belong to a peer group is directly correlated to the success, acceptance and happiness of a teenager [12].

Considering all the above factors, the current study aims to understand the prevalence of body image issues among adolescent boys in Mumbai

\section{METHODOLOGY}

\section{Sample}

173 boys (age group 12-20) -from schools (for early adolescents) and colleges (for late adolescents) located in Western Suburbs of Mumbai. The incidental sampling method was used. These were early adolescents $(12-15$ years $)(\mathrm{N}=75)$ and late adolescents $(16-20$ years $)(\mathrm{N}=98)$.

\section{Tool used}

A 26 item questionnaire was self constructed and had open ended items (item number 3, 7, 18), likert scale (5 point) items (item number 1, 2, 4, 8, 9, 14, 15, 16, 19, 20, 24, 25, 26), multiple choice questions items (item number 5, 6, 17, 18, 21, 22), Binary choice items (item number 11, 12, 23), Pictorial choice item (item number 10) An interview using pre-designed, semi- structured, open ended questions for qualitative understanding of the subject by parents and gym instructors.

\section{RESULTS}

The t-test for random measures was utilized to compare the means scores of the two groups and check if there is any significant difference between the 2 groups. The choice of inferential statistic depends on the specific way in which the dependent variable is being measured and since it is mean scores of two groups (interval scale) the t-test was appropriate. The t-test for random measures was used as the 2 samples were independent of each other.

Table 1 - Mean difference between how often parents and peers comment on the body of adolescent boys

\begin{tabular}{|c|c|c|c|c|}
\hline \multicolumn{2}{|c|}{$\mathbf{N}$} & Mean & t value & df \\
\hline \multirow{2}{*}{$\begin{array}{l}\text { Parents (early) v/s } \\
\text { Parents (late) }\end{array}$} & \multirow[t]{2}{*}{173} & 2.17 & \multirow[t]{2}{*}{$-2.77^{*}$} & \multirow[t]{2}{*}{171} \\
\hline & & 2.66 & & \\
\hline \multirow{2}{*}{$\begin{array}{l}\text { Peers (early) v/s } \\
\text { Peers (late) }\end{array}$} & \multirow[t]{2}{*}{173} & 2.16 & \multirow[t]{2}{*}{ NS } & \multirow[t]{2}{*}{171} \\
\hline & & 2.31 & & \\
\hline \multirow{2}{*}{$\begin{array}{l}\text { Parents (early) v/s } \\
\text { Peers (early) }\end{array}$} & \multirow[t]{2}{*}{150} & 2.17 & \multirow[t]{2}{*}{ NS } & \multirow[t]{2}{*}{74} \\
\hline & & 2.16 & & \\
\hline \multirow{2}{*}{$\begin{array}{l}\text { Parents (late) v/s } \\
\text { Peers (late) }\end{array}$} & \multirow[t]{2}{*}{196} & 2.66 & \multirow[t]{2}{*}{$-2.29^{* *}$} & \multirow[t]{2}{*}{97} \\
\hline & & 2.31 & & \\
\hline
\end{tabular}

$* \mathrm{p}<0.01$; significant, ${ }^{* *} \mathrm{p}<0.05$; significant, ns: not significant 
The Chi-square test was employed to see if there existed a significant difference between the 2 categorical variables (same gender v/s opposite gender). This statistical tool was utilized as the scale of measurement of the items was nominal.

\section{DISCUSSION}

According to the data analysis, it was observed that more than half of respondents in both the stages reported that they were satisfied with their body. As they progress from early to late adolescents, their concerns regarding their body image also increases, they feel more insecure about their bodies. It can also be seen that late adolescents placed more importance on their appearance than early adolescents. Most respondents found the ideal body type to be fit; ripped and built. Out of a sample of 173 adolescents, not a single adolescent pictured skinny fat, chubby fat and obese fat as an ideal body. This shows the prevalence of underlying body stereotypes against being obese, overweight or underweight. As an alternate explanation, it could also mean that the adolescents are health conscious and did not opt for those options because of the health hazards that come with poor health. These choices of adolescents show their concept of a perfect size. The data from another question showed that nearly one third of the sample across each age group worried about not being the "perfect" size, and it was seen that more late adolescents felt pressurized to look good. As a result, the acceptance and appreciation for the ideal chiseled body causes any individual with a differing body to feel awkward and in some instances to also avoid activities which may reveal one's body like swimming and exercising. This is at par with the study that says that a significant number of boys were told by their peers that they would look better if they were muscular [13].

Table 2 - Frequencies showing the significance of how the gender of the peer helps shape the idea of the perfect body in adolescent boys

\begin{tabular}{|ll|}
\hline \multicolumn{1}{|c|}{$\mathrm{X}^{2}$} \\
\hline $\begin{array}{l}\text { Same gender v/s } \\
\text { opposite gender } \\
\text { (early) }\end{array}$ & $8.33^{*}$ \\
\hline $\begin{array}{l}\text { Same gender v/s } \\
\text { opposite gender (late) }\end{array}$ & $19.75^{* *}$ \\
\hline${ }^{*} \mathrm{p}<0.01 ;$ significant, ${ }^{* *} \mathrm{p}<0.01 ;$ significant
\end{tabular}

It was found that majority of the respondents felt that their parents hardly commented on their body, although it was more in early adolescents than late. The occurrence of comments was more frequent by parents towards late adolescents on a weekly and daily basis as compared to early adolescents. Further analysis was conducted to test for the significance between these differences using a one tailed t-test for random measures. The $\mathrm{t}$-value was $\mathrm{t}_{(171)}=-2.77, \mathrm{p}<0.01$. This data was found to be significant, hence it can be said that it wasn't based on chance. The regularity of comments by peers and parents on late adolescents was analyzed. It was found that majority felt that their parents and peers hardly commented on their body. The respondents felt that on a daily basis their parents commented on their bodies three times more than their peers did. A similar trend was observed where they also said that their parents commented more than their peers multiple times a day. Further analysis was conducted to test for the significance between these differences using a one tailed $t$-test for random measures. The t-value was $t_{(171)}$ $=-2.29, \mathrm{p}<0.05$. This data was also found to be significant, hence it can be said that it wasn't based on chance. However, when analysis was done on early adolescents the data showed that they felt that their parents and peers commented on their body equally. However, on analyzing the data via one tailed t-test for random measures the difference was found to be not significant and could therefore be due to chance. 
Parents are known to be important agents of socialization who can influence an adolescent boy's body image through modeling, feedback and instruction. This interaction between parents and adolescent boys places great value on the beauty and the importance of appearance. While growing up, boys tend to see their defects as parents see them and this causes them to internalize such messages about their bodies. Parents of adolescent boys can be concerned about their son's weight and body and can advise the adolescent to lose weight. For late adolescents, parents were seen to be a bigger cause for body image concerns than for early adolescents [14-15].

Due to such value being placed on their appearance, adolescent boys may feel pressurized to look good. The personal interviews of parents (with one or more sons) reaffirmed the influence of parents in the early years of adolescence. The parents were given two hypothetical situations, one in which their child was underweight and the other in which he was overweight, and then they were asked for the course of action. Majority of the parents were concerned with an underweight child and reported that they would take him to a doctor and seek best advice. Parents strongly denied ever teasing their son based on his physique; however on probing, some parents did acknowledge the same. The collectivistic model of society observed in Asian countries might be one of the reasons as to why parents felt responsible for a positive body image among their sons.

Peers form the first social distinct unit where an individual applies the social etiquettes that they first acquire from their family. Adolescence is a stage where there is an increased intimacy in friendship and this closeness further helps shaping the social context of adolescents. Two major aspects of peer involvements that shape the contribution to body image are appearance conversation with friends and appearance criticism from peers. Amongst the two stages, more late adolescent boys reported to comparing their body with their peers. The perception of their peers with regard to their physique was found to be quite important for the boys in both stages. Thus, reiterating that peers and their opinions do matter to adolescents. Peer criticism about appearance is a well-established truth in the lives of adolescents. It was observed that most adolescents hardly felt that they were being teased because of their physique. But a relatively smaller percentage of boys did feel so and this cannot be left unattended. Even though a similar percentage of respondents reported being teased from both stages, the incidence rate in early adolescents was higher. More late adolescents reported being commented on by their peers than early adolescents. However with further analysis via one-tailed t-test for random measures the data was found to be not significant and hence could be due to chance. Due to the increased social interactions in this stage, as they start getting older, adolescents begin to feel the pressure to look good and this was evident from the results obtained. Through the research conducted, it was observed that the adolescents in each stage reported significantly differing accounts regarding their body image that formed a trend [1618].

Regarding body image concerns, it was found that more late adolescents were concerned about their body weight and related parameters than early adolescents. Another trend that highlights the difference between the two stages is one that measured how the adolescent feels about his body. More late adolescents said that they feel fine about their body compared to early adolescents. Albeit marginally, more early adolescents felt the need to lose weight than did late adolescents. It was found that the most common method employed by adolescents to address their body image concerns was using the gym. On interviewing gym instructors, it was found that most adolescent boys started using the gym by the age of 15. According to the data collected, more parents are seen to comment about their son's body in the late adolescent stage. Peers perception of their physique was regarded to be important by boys of all ages. When it comes to triggering body image concerns, more late adolescents attributed parents and peers to be a greater cause. In both stages, the impact of peers on their body image concerns was seen to be higher than that of their parents but this difference was greater in late adolescents.

\section{REFERENCES}


1. Schilder P. The image and appearance of the human body. Routledge; 2013.

2. Grogan S. Body image: Understanding body dissatisfaction in men, women and children. Routledge; 2016.

3. McCabe MP, Ricciardelli LA. Body image dissatisfaction among males across the lifespan: A review of past literature. J Psychosom Res 2004;56(6):675-85.

4. Stormer SM, Thompson JK. Explanations of body image disturbance: A test of maturational status, negative verbal commentary, social comparison, and sociocultural hypotheses. Int J Eating Disord 1996;19(2):193202.

5. Mclaren L, Kuh D, Hardy R, Gauvin L. Positive and negative body-related comments and their relationship with body dissatisfaction in middle-aged women. Psychol Health 2004;19(2):261-72.

6. Botta RA. For your health? The relationship between magazine reading and adolescents' body image and eating disturbances. Sex Roles 2003;48(9):389-99.

7. Smolak L. Body image in children and adolescents: where do we go from here?. Body Image 2004;1(1):1528.

8. Field AE, Sonneville KR, Crosby RD, Swanson SA, Eddy KT, Camargo CA, Horton NJ, Micali N. Prospective associations of concerns about physique and the development of obesity, binge drinking, and drug use among adolescent boys and young adult men. JAMA Pediatrics 2014;168(1):34-9.

9. Botta RA. Television images and adolescent girls' body image disturbance. J Commun 1999;49(2):22-41.

10. Krayer A, Ingledew DK, Iphofen R. Social comparison and body image in adolescence: a grounded theory approach. Health Educ Res 2008;23(5):892-903.

11. Ricciardelli LA, McCabe MP, Banfield S. Body image and body change methods in adolescent boys: Role of parents, friends and the media. J Psychosom Res 2000;49(3):189-97.

12. Collins ME. Body figure perceptions and preferences among preadolescent children. Int J Eating Disord 1991;10(2):199-208.

13. Joseph R. The right cerebral hemisphere: Emotion, music, visual-spatial skills, body-image, dreams, and awareness. J Clin Psychol 1988;44(5):630-73.

14. McCabe MP, Ricciardelli LA. Sociocultural influences on body image and body changes among adolescent boys and girls. J Soc Psychol 2003;143(1):5-26.

15. Fisher S. Development and structure of the body image. Psychology Press; 2014.

16. Jones DC. Social comparison and body image: Attractiveness comparisons to models and peers among adolescent girls and boys. Sex Roles 2001;45(9):645-64.

17. Dohnt HK, Tiggemann M. Body image concerns in young girls: The role of peers and media prior to adolescence. J Youth Adolesc 2006;35(2):135-45.

18. Jones DC, Vigfusdottir TH, Lee Y. Body image and the appearance culture among adolescent girls and boys: An examination of friend conversations, peer criticism, appearance magazines, and the internalization of appearance ideals. J Adolesc Res 2004;19(3):323-39.

\section{Acknowledgements}

Dr. Jennie Mendes, Associate Professor, Department of Psychology, Sophia College for Women, Mumbai

$$
\begin{aligned}
& \text { Source of Funding - Nil } \\
& \text { Conflict of Interest - Nil }
\end{aligned}
$$

